\title{
Nonlinear Characteristics of the Pile Soil System under Vertical Vibration
}

\author{
Mohammad Amin Rashidifar,", Ali Amin Rashidifar ${ }^{2}$, Abdolah Abertavi $^{3}$ \\ ${ }^{1}$ Department of Mechanical Engineering, Islamic Azad University, Shadegan Branch, Iran \\ ${ }^{2}$ Department of Computer Science, Islamic Azad University, Shadegan Branch, Iran \\ ${ }^{3}$ Department of Electrical Engineering, Islamic Azad University, Shadegan Branch, Iran
}

Copyright $\mathrm{C} 2016$ by authors, all rights reserved. Authors agree that this article remains permanently open access under the terms of the Creative Commons Attribution License 4.0 International License

\begin{abstract}
In this paper, the inverse problem of the nonlinear vibration of pile foundations has been studied. The methodology proposed by Novak is used to identify the parameters of the soil-pile system from the measured response displaying nonlinear features. A comprehensive study involving both vertical dynamic testing of piles and theoretical analysis is described. The dynamic tests are carried out on single and $2 \times 2$ group piles in the field under varying levels of vertical harmonic load. From the measured nonlinear response curves, the effective pile-soil system mass, stiffness and damping are determined using the methodology of Novak assuming nonlinear restoring force and linear damping force. It is found that the stiffness of pile-soil system markedly decrease with increasing exciting intensity but the damping increase with exciting moments. Finally the dynamic responses of piles are back-calculated using the estimated nonlinear parameters. It is found that theoretical nonlinear response curves agree well with that obtained from vertical vibration tests.
\end{abstract}

Keywords Novak Methodology, Nonlinear Vibration, Dynamic Testing, Harmonic Load

\section{Introduction}

The dynamic response of piles subjected to vertical excitation involves complicated pile-soil interaction. Piles behave in a nonlinear fashion when displacement of the pile is large. This nonlinearity is the result of nonlinear soil behavior at high strain level, pile separation and slippage with the soil. A further complication in this response comes from the interaction between the piles in a pile group. For a closely spaced pile group, there is a significant effect on one pile to another pile during the application of dynamic loading causing propagation of wave through the soil from each pile under load.

An accurate theoretical solution to dynamic pile-soil interaction incorporating slippage and nonlinearity is quite complex. This encourages developing various approximate methods. Matlock et al. [5] introduced lumped mass models with nonlinear discrete springs, dashpot, and friction elements. Another approximate approach, which includes a weak cylindrical zone or inner boundary zone around the pile, was proposed by Novak \& Sheta [8]. One of the simplifications involved in the original boundary-zone concept was that the inner zone was neglected to avoid the wave reflections from the interface between the inner boundary zone and the outer zone. To overcome this problem Veletsos \& Dotson [10] proposed a scheme that can account for the mass of the boundary zone. El Naggar \& Novak [2] presented a model for the analysis of axial pile response allowing for nonlinear soil behaviour, energy dissipation through radiation damping, and soil hysteresis.

Although there are a number of methods available for analyzing the dynamic response of piles, very little information is available on the field validation of the problem. Full scale dynamic tests on pile were conducted in the field by Vaziri \& Han [9]. Novak \& Grigg [7] conducted the dynamic experiments on small-scale single piles and pile groups in the field. Similar field dynamic tests on small scale piles were conducted by Han \& Vaziri [3], Burr et al. [1] and Manna \& Baidya [4].

The objective of the present investigation is to study the nonlinear dynamic behavior of piles under strong vertical excitation. A comprehensive study involving both model dynamic testing of pile foundation and theoretical analysis is described. The dynamic tests were carried out on model reinforced concrete single pile and $2 \times 2$ pile groups. Frequency versus amplitude curves of piles were experimentally obtained in the field for different intensities of excitation. Finally the observed response is compared with theoretical solutions. First the effective pile-soil system mass, stiffness and damping are determined using the methodology proposed by Novak [6] from the measured nonlinear frequency amplitude response curves. The nonlinear response curves are then back-calculated using the theory of nonlinear vibration and the results are compared with the test results. 

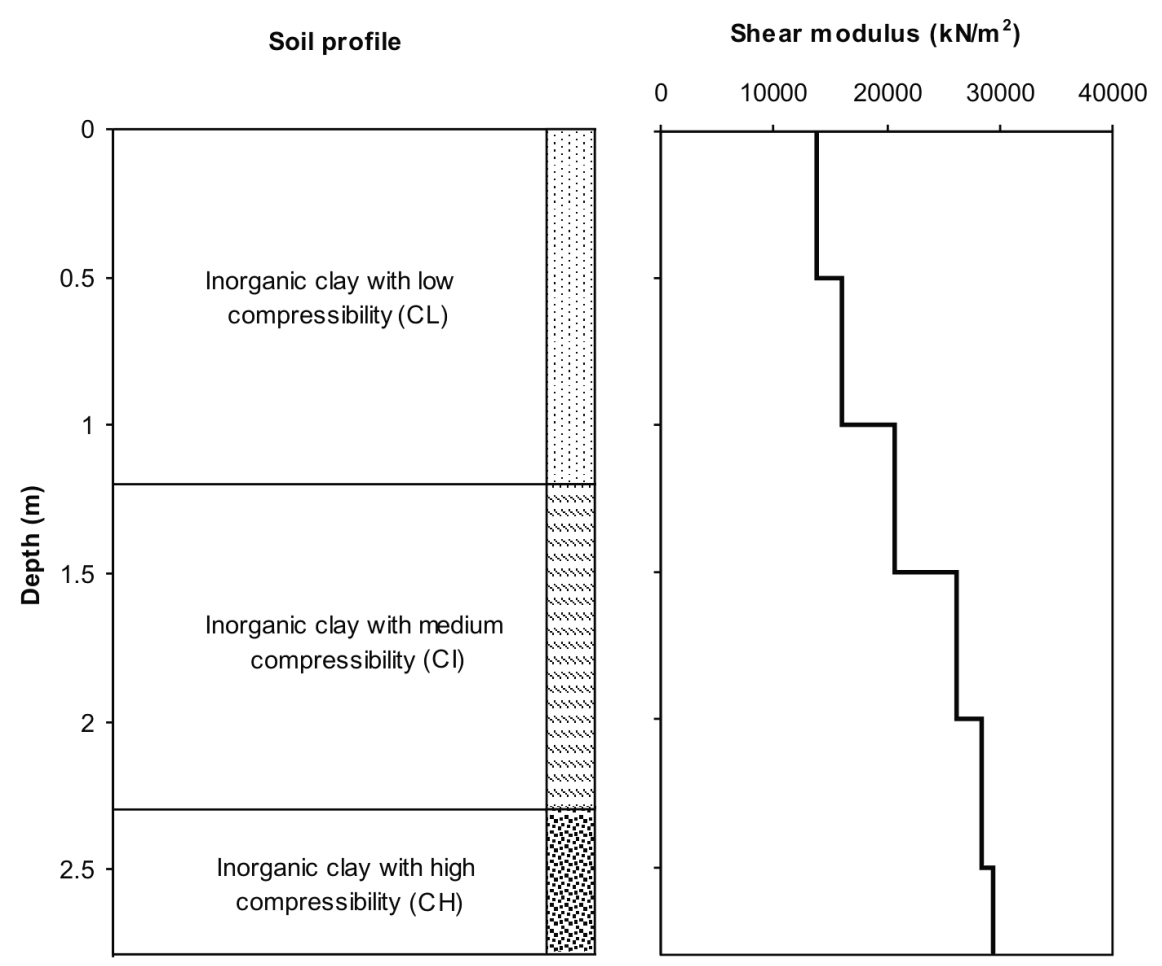

Figure 1. Variation of Soil Profile and Shear Modulus with Depth

\section{Experimental Investigations}

\subsection{Site and Soil Condition}

The site was located adjacent to Hangar, at Indian Institute of Technology, Kharagpur Campus, India. Both disturbed and undisturbed soil samples were collected from three bore holes located at different places of the site. The soil properties were determined by in situ and laboratory tests. Two different in situ tests were conducted, namely, Standard Penetration Tests (SPT) to determine $N$ value and cross hole seismic tests for determining the shear wave velocity of soil layer. The different soil profile and the variation of shear modulus of different soil strata are presented in Figure 1. The piles were constructed in the field by bored cast in situ method. The diameter $(d)$ of the pile was $0.1 \mathrm{~m}$. In this study, single pile ( $L / d=20$, where $L$ is pile length, $d$ is pile diameter) and group pile $(L / d=15, s / d=4$, where $s$ is the spacing of pile in a group) were used for the investigation. The dimension of pile cap was $0.57 \mathrm{~m} \times 0.57 \mathrm{~m} \times 0.25 \mathrm{~m}$.

\subsection{Vertical Vibration Tests and Measured Response}

Forced vibration tests were conducted on model piles subjected to vertical vibration. In order to connect the pile cap to the oscillator, a rigid mild steel plate was attached rigidly on the pile cap with nut and bolt. Lazan type mechanical oscillator was mounted over the steel plate. To ensure that the resonance peaks were well pronounced and within the frequency range of the exciting mechanism, mild steel ingots or test bodies were rigidly bolted on the top of the oscillator. The test body was comprised of steel ingots each weighing $650 \mathrm{~N}$ ( 8 nos.) and $450 \mathrm{~N}$ (10 nos.). Whole set up was then connected so that it acted as a single unit. A flexible shaft was used to connect the mechanical oscillator to a DC motor. The motor was connected to a speed control unit to control the speed of the DC motor. The vibration measuring equipment consisted of a two piezoelectric acceleration pickup and vibration meter. For vertical excitation, displacements were measured using two acceleration pickups. The schematic diagram of the experimental setup is shown in Figure 2. 


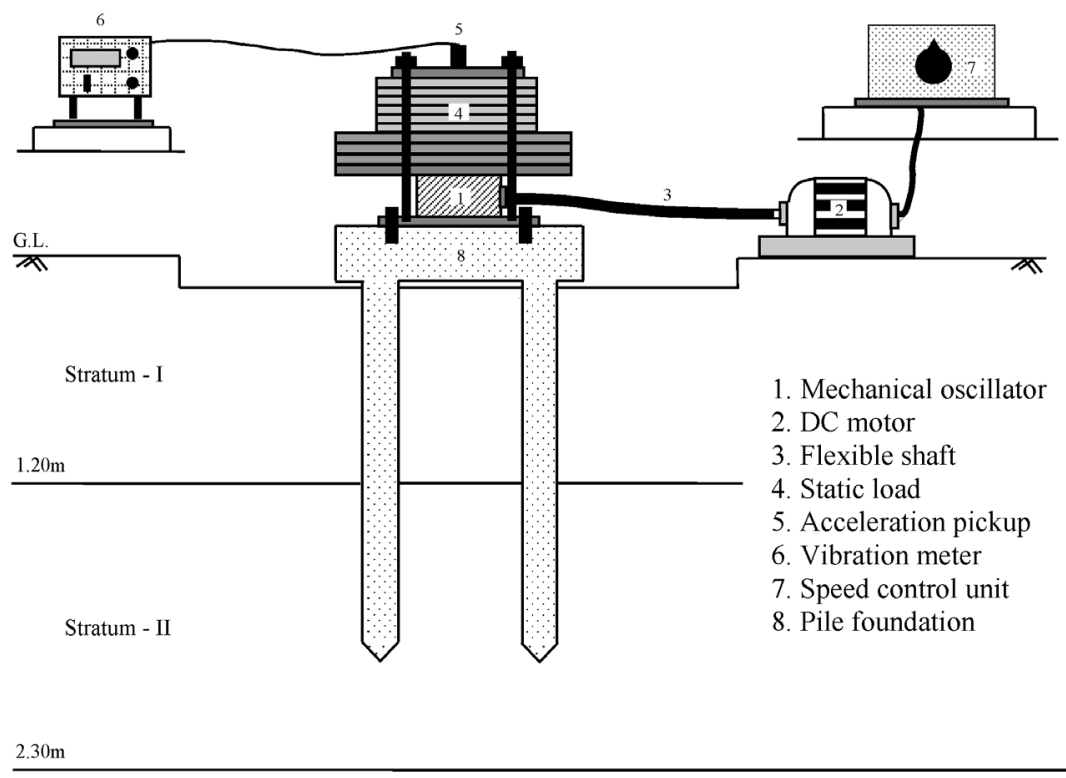

Stratum - III

Figure 2. Schematic Diagram of Test Setup for Vertical Vibration

The oscillator was then run slowly through a motor using speed control unit to avoid sudden application of high magnitude dynamic load. Frequency and corresponding vertical amplitude of vibration was recorded by photo tachometer and vibration meter, respectively. Finally, frequencies versus displacement amplitude curves were plotted.

Two different static loads ( $10 \mathrm{kN}$ and $12 \mathrm{kN}$ including the weight of the pile cap and oscillator) were used in both the cases. For each static load, tests were conducted at four different eccentric moments W.e $(0.187,0.278,0.366$, and $0.450 \mathrm{~N}-\mathrm{m}$, where $W$ is weight of eccentric rotating part in oscillator and $e$ is eccentricity of rotating part of the oscillator) by adjusting the angle of eccentric mass. Tests were carried out for two different embedded depths $(h)$ of pile cap: Case 1 -Pile cap embedded into soil $(h=0.175 \mathrm{~m})$; Case 2 - No contact of pile cap with soil $(h=0)$. Steady state dynamic response to harmonic excitation was measured under different frequencies for all eccentric moments at each static load.

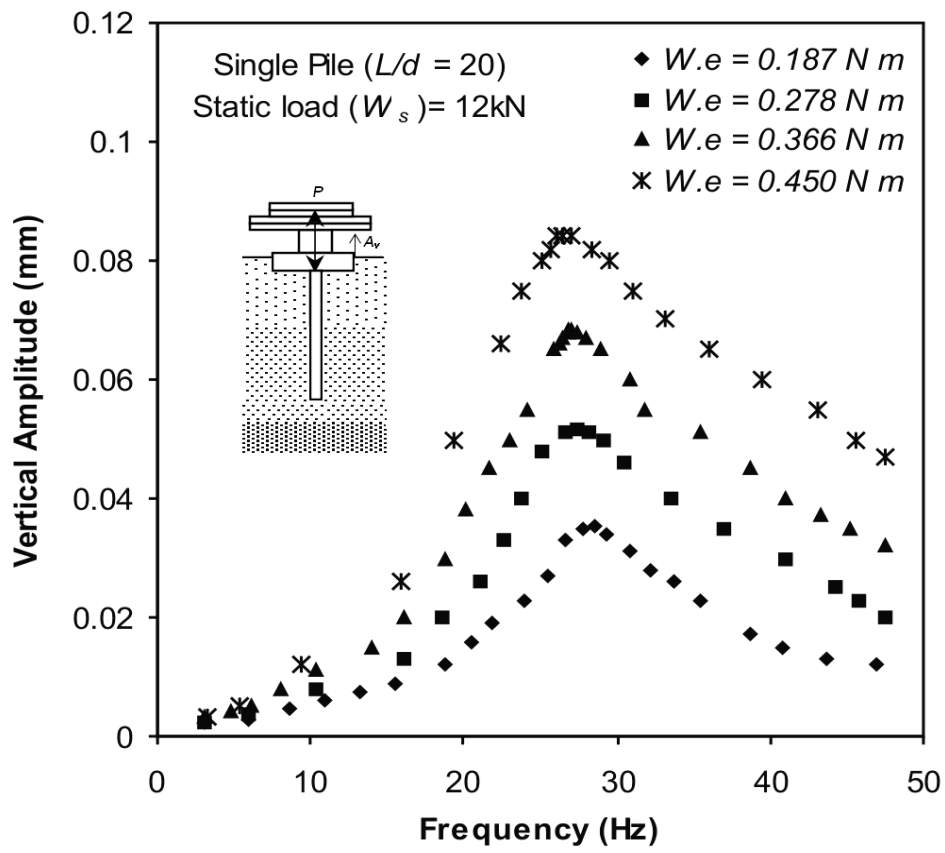

Figure 3. Frequency versus Amplitude Response of Pile under Vertical Vibration (Single pile, L/d =20, Ws $=12 \mathrm{KN}$, Case 1). 
A typical frequency versus amplitude curve of vertical vibration for single pile is shown in Figure 3. It can be seen that the observed response curves display nonlinearity as the resonant frequencies decreases with increasing excitation intensity and also the amplitudes are not proportional to the excitation intensity. The effects of static loads on the vertical dynamic response of piles are studied and it is observed that both the natural frequency and resonant amplitude decreases as the static load increases. At the embedded condition of pile cap it shows higher resonant frequency than the no contact condition of pile cap. However, the resonant amplitude is always higher in case of no contact condition than in case of embedded pile cap.

\section{Evaluations of Nonlinear Response and Comparison with Observed Data}

The effective mass, stiffness and damping are determined and the nonlinear response curves are back-calculated using the theory of nonlinear vibration from the measured nonlinear response curves. The methodology of the inverse problem suggested by Novak [6] is used. This study was confined to the inverse problem of steady state oscillation excited by a harmonic force whose amplitude varies with the square of excitation frequency. It was also assumed that the stiffness of pile-soil system was independent of frequency. The reduction of resonant frequency is recognized using backbone curve which can be established on the measured response curve. The backbone curve describes the variation of the undamped resonant frequencies $\Omega(A)$ with amplitude. A simple relation that was proposed by Novak (1971) is given by,

$$
\Omega=\sqrt{\omega_{1} \omega_{2}}
$$

Where: $\omega_{1}$ and $\omega_{2}$ are the frequencies corresponding to the points of interaction of the response curve and a line passing through the origin. Two sets of response curve, (Set 1: Single pile, $L / d=20, W_{s}=10 \mathrm{kN}$, Pile cap embedded into soil; Set 2: Pile group, $2 \times 2, \mathrm{~L} / \mathrm{d}=15, \mathrm{~s} / \mathrm{d}=4, \mathrm{Ws}=12 \mathrm{kN}$, No contact of pile cap with soil) where maximum nonlinearity was observed, were chosen. The backbone curve $\Omega$ was constructed for each response curve by intersecting the experimental response curves by a trace of lines as shown in Figures 4 (a) and (b) for single and group pile, respectively.

It can be observed that each response curve has its own backbone curve but the nature of these backbone curves is different for single pile from group pile. From the nature of backbone curve it can be seen that the stiffness characteristic of the pile-soil system varies with excitation intensity. The stiffness characteristics of system can be established corresponding to the individual backbone curves for single and group pile.

The stiffness characteristic can be expressed assuming the restoring force $F\left(A_{s}\right)$ as nonlinear for every steady state amplitude $A_{s}$ as:

$$
K_{e}\left(A_{s}\right)=\frac{F\left(A_{s}\right)}{A_{s}}
$$

The restoring force can be expressed by a power series as

$$
F\left(A_{s}\right)=k_{1} A_{s}+k_{2} A_{s}^{3}+k_{5} A_{s}^{5}+\ldots+k_{n} A_{s}^{n}
$$

Where $k_{1}, k_{2} \ldots k_{n}$ are constants.

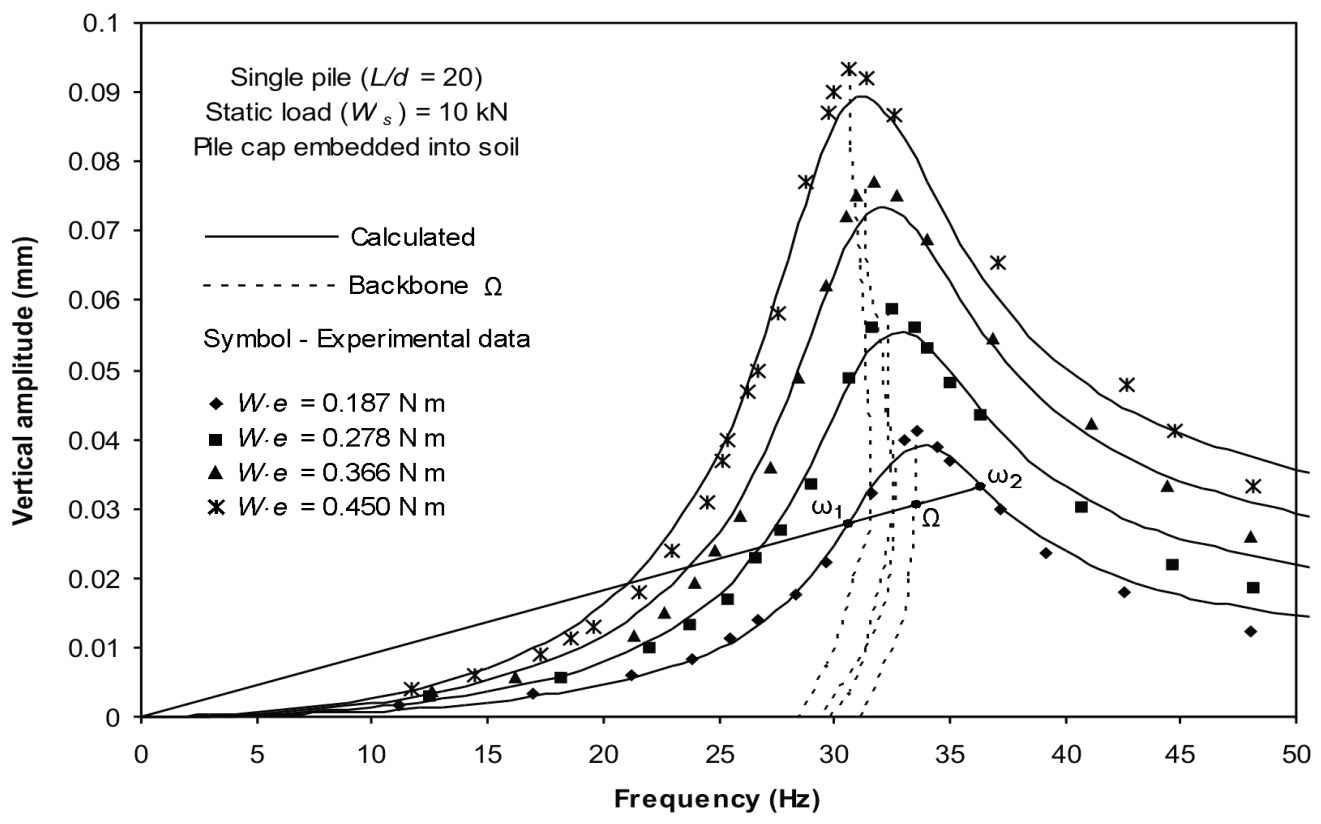




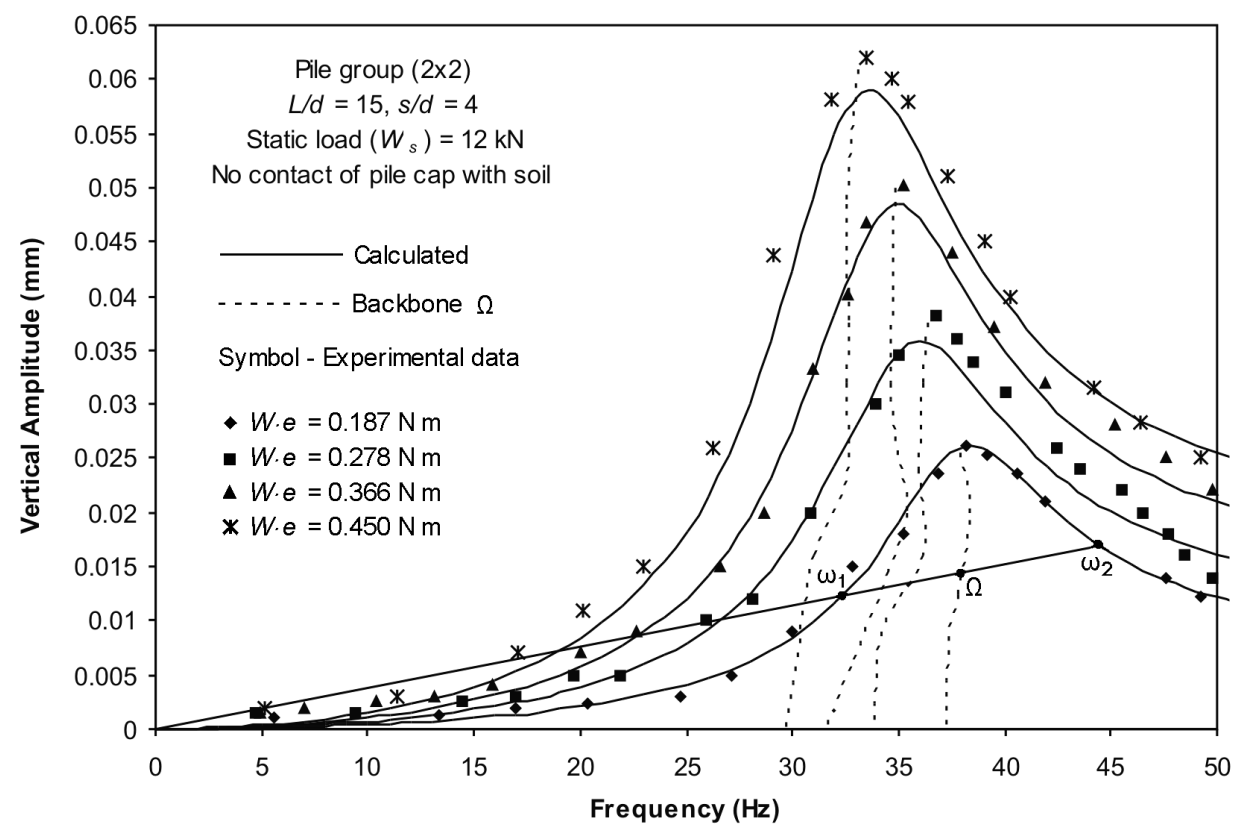

(b)

Figure 4. Experimental and Back Calculated Response Curves under Vertical Vibration: (a) Single Pile and (b) Group Pile.

The amplitude dependent resonant frequency is given by:

$$
\Omega^{2}\left(A_{s}\right)=\sqrt{\frac{K_{e}\left(A_{s}\right)}{m_{e f f}}}=\left(\frac{1}{m_{e f f}}\right)\left(k_{1}+k_{3} A_{s}^{2}+k_{5} A_{s}^{4}+\ldots k_{n} A_{s}^{n-1}\right)
$$

Where: $m_{\text {eff }}$ is the effective mass of the system. The damping and effective mass can be determined in several ways using the geometric properties of the nonlinear response curves. For the nonlinear response, the effective mass $\left(m_{e f f}\right)$ is much greater than the mass of total static load ( $m_{s}=W_{s} / g ; W_{s}$ is the total static load on pile, $g$ is the acceleration due to gravity). The apparent additional mass can be expressed in terms of the coefficient as

$$
\xi=\frac{m_{e f f}-m_{s}}{m_{s}}
$$

The effective mass and damping are obtained based on above method and summarized in Table 1. It can be seen from Table 1 that the effective mass decreases and damping increases with increasing excitation intensities. The lower values of additional effective mass at higher excitation indicate that partial separation might have occurred with higher excitation intensity.

The characteristics of the restoring force can be determined from the backbone curve, $\Omega$, and the calculated values of effective mass for each response curve as

$$
F\left(A_{s}\right)=A_{s} m_{e f f} \Omega^{2}
$$

Table 1. Nonlinear Parameters of Piles in Vertical Direction

\begin{tabular}{|c|c|c|c|c|}
\hline \multirow{2}{*}{$\begin{array}{c}\text { Exciting } \\
\text { moment } \\
(\mathrm{N} \mathrm{m})\end{array}$} & $\begin{array}{c}\text { Mass } \mathrm{m}_{\text {eff }} \\
\mathrm{kg})\end{array}$ & Mass coefficient $(\xi)$ & \multirow{2}{*}{ Damping } & $\begin{array}{c}\text { Stiffness } \\
(\mathrm{kN} / \mathrm{mm})\end{array}$ \\
\cline { 2 - 5 } & \multicolumn{5}{|c|}{ Single pile (L/d =20) } \\
\hline 0.187 & 2298.78 & 1.29 & 0.106 & 101.09 \\
\hline 0.278 & 2156.28 & 1.15 & 0.119 & 88.88 \\
\hline 0.366 & 2055.66 & 1.05 & 0.125 & 81.05 \\
\hline 0.450 & 2008.97 & 1.00 & 0.129 & 74.50 \\
\hline \multicolumn{5}{|c|}{ Pile group (L/d = 15, s/d = 4) } \\
\hline 0.187 & 3458.10 & 1.88 & 0.107 & 196.49 \\
\hline 0.278 & 3343.39 & 1.78 & 0.120 & 166.40 \\
\hline 0.366 & 3234.74 & 1.69 & 0.125 & 151.05 \\
\hline 0.450 & 3068.81 & 1.55 & 0.134 & 132.13 \\
\hline
\end{tabular}

From the response curves the restoring force and corresponding displacement are obtained and plotted in Figures 5(a) and (b) for single and group pile, respectively. 


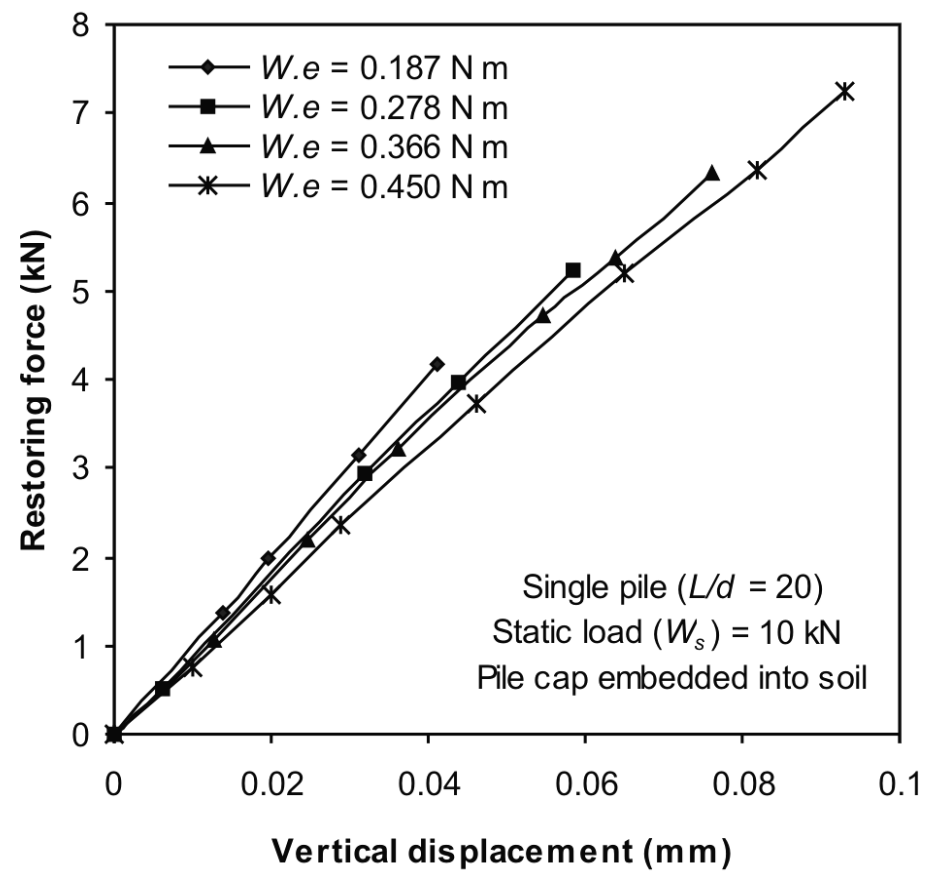

(a)

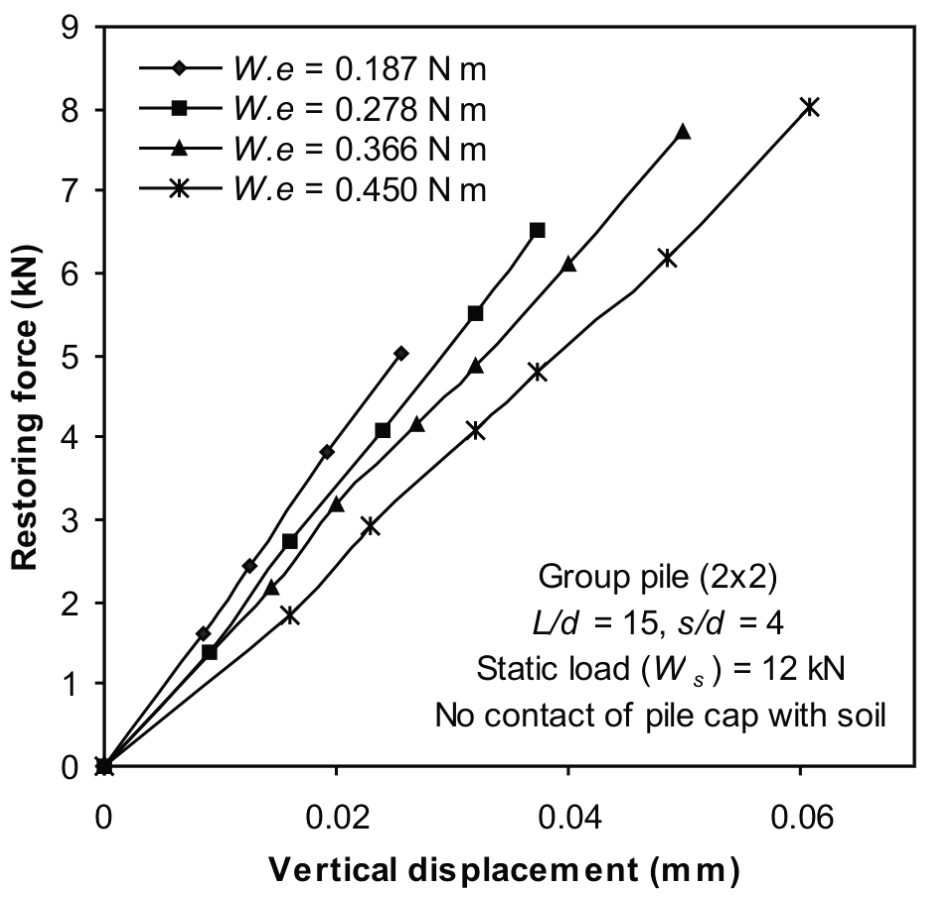

(b)

Figure 5. Pile Restoring Force Characteristic versus Pile Displacement: (a) Single Pile and (b) Group Pile.

The tangent at the origin determines the stiffness of the system. It is observed that the overall stiffness decreases with increasing excitation intensity. The values of the stiffness for different excitation intensities are summarized in Table 1 . The nonlinear response curves (solid lines in Figs $4 \mathrm{a}$ and $\mathrm{b}$ ) are back calculated using the nonlinear theory with the calculated pile-soil system mass, damping, and the characteristic of restoring force. It can be seen that theoretical nonlinear response curves agree with the measured data quite well for vertical vibrations. Hence a comprehensive and straight forward theoretical analysis is possible with the system having a nonlinear restoring force and linear damping.

\section{Conclusions}

A comprehensive study involving both dynamic testing of pile foundation and theoretical analysis (Novak 1971) are described in the paper. Vertical vibration tests with model 
reinforced concrete single and group piles embedded in layered soil were conducted in the field. A large number of tests with different exciting intensities and different embedded conditions of pile cap were considered. The observed pile response exhibits typical nonlinear behavior. From the measured vertical response curves, the effective pile-soil system mass, stiffness and damping have been determined and the nonlinear response curves are back-calculated using the theory of nonlinear vibration. It is found that a good agreement can be achieved between the experimental and back-calculated response curve using vertical nonlinear parameter determined from the measured nonlinear response curves.

\section{REFERENCES}

[1] Burr J.P., Pender M.J. and Larkin T.J. (1997). "Dynamic Response of Laterally Excited Pile Groups", Jl. of Geotech. \& Geoenviron. Eng., ASCE, 123(1): 1-8.

[2] El Naggar M. H. and Novak M. (1994). "Non-Linear Model for Dynamic Axial Pile Response", Jl. of Geotech. Eng., ASCE 120(2): 308-329.
[3] Han Y. and Vaziri H. (1992). "Dynamic Response of Pile Groups under Lateral Loading”, Soil Dyn. and Earthq. Eng., 11: 87-99.

[4] Manna B. and Baidya D.K. (2009). "Dynamic Vertical Response of Model Piles-Experimental and Analytical Investigations", Int. Jl. of Geotech. Eng., 3(2): 271-287.

[5] Matlock H., Foo H C. and Bryant L.M. (1978). "Simulation of Lateral Pile Behaviour under Earthquake Motion”, In: Proc. ASCE. Specialty Conf. on Earthq. Eng. and Soil Dyn., XI: 600-619. Pasadna, CA.

[6] Novak M. (1971). "Data Reduction from Nonlinear Response Curves", Jl. of Eng. Mech., ASCE, 97(EM4): 1187-1204.

[7] Novak M. and Grigg R.F. (1976). "Dynamic Experiments with Small Pile Foundations", Can. Geotech. Jl., 13: 372-385.

[8] Novak M. and Sheta M. (1980). "Approximate Approach to Contact Problems of Piles", Proc: Dyn. Response of Pile Found: Analytical Aspects, M. O'Neill et al., eds., ASCE: 53-79. New York.

[9] Vaziri H. and Han Y. (1991). "Full-scale Field Studies of the Dynamic Response of Piles Embedded in Partially Frozen Soils", Can. Geotech. Jl., 28: 708-718.

[10] Veletsos A.S. and Dotson, K.W. (1988). "Vertical and Torsional Vibration of Foundations in Inhomogeneous Media", Jl. of Geotech. Eng., ASCE, 114(9): 1002-1021. 